\title{
Unha cantiga lésbica amatoria no trobadorismo galego-portugués
}

\author{
A love lesbian cantiga in Galician-portuguese troubadorism
}

\author{
Carlos Callón \\ carloscallon@carloscallon.com \\ Instituto Espanbol de Lisboa \\ Universidade de Santiago de Compostela
}

Resumo: A cantiga «Dizia la ben-talhada», atribuída ao trobador galego-portugués Pedr'Eanes Solaz, presentouse na maioría das edicións dos séculos XIX e XX (e nalgunhas do XXI) a través da modificación de pronomes femininos en masculinos, para denotar unha relación heterosexual que non figura no texto. Neste artigo desenvólvense as diferentes hipóteses interpretativas sobre a composición, en diálogo con outros textos literarios medievais semellantes (romances, mediolatinos e andalusís). Conclúese que a hipótese máis probábel á luz dos datos de que se dispón é que se trata dunha composición amatoria entre dúas mulleres e que como tal debe ser restituída a súa edición.

Palabras chave: lesbianismo, queer studies, cantigas galego-portuguesas, trobadorismo, edición textos medievais

\begin{abstract}
The cantiga «Dizia la ben-talhada», attributed to the Galician-Portuguese troubadour Pedr'Eanes Solaz, appeared in most of the editions of the 19th and 20th century (and in some of the 21st) modificating feminine pronouns into masculine, to denote a heterosexual relationship that does not appear in the text. In this article are developed the different interpretive hypotheses on composition, in dialogue with other similar medieval literary texts (Romance, mid-Latin and Andalusian). It is concluded then that the most likely hypothesis, in the light of the available data, is that it is an amateur composition between two women and that as such, it should be restored to its edition..
\end{abstract}

Keywords: lesbianism, queer studies, Galician-Portuguese cantigas, troubadours, medieval text edition 
As tres liñas canónicas do trobadorismo profano galego-portugués son, como é sabido, as cantigas de amor, as cantigas de amigo e as cantigas de escarnio e maldizer. Eses tres grandes grupos textuais son moi maioritarios nos testemuños que chegaron até nós e tamén aparecen na fragmentaria e anónima Arte de trobar. ${ }^{1}$ A ese único tratado en prosa das escolas trobadóricas galego-portuguesas fáltanlle os capítulos iniciais, nos cales se supón que se diferenciarían xustamente as cantigas de amigo e as cantigas de amor. No entanto, o que si conservamos comeza falando dos cantares dialogados e fai referencia ás partes hoxe perdidas:

E porque algũas cantigas i há en que falan eles e elas outrossi, por én é ben de entenderdes se son d'amor, se d'amigo: porque sabedes que, se eles falan na prim[eir]a cobra e elas na outra, [son d']amor, porque se move a razon deles, como vos ante dissemos, e se elas falan na primeira cobra, é outrossi d'amigo, e se ambos falan en ũa cobra, outrossi é segundo qual deles fala na cobra primeiro (Capítulo IIII, Arte de Trovar, Cancioneiro da Biblioteca Nacional).

Por tanto, unha cantiga enunciada en masculino ou comezada en masculino cae do lado do conxunto «de amor», e unha cantiga enunciada en feminino ou comezada en feminino cae do lado «de amigo». ${ }^{2}$ É importante notar que as cantigas de amigo son, cuantitativamente, o maior repertorio de textos en que fala unha muller en toda a tradición occidental premoderna (Cohen 2003), tan relevante como lembrarmos que todos os textos que conservamos están asinados por homes. Esta ausencia das mulleres nas autorías que se preservaron non é un elemento unánime no trobadorismo europeo. Por exemplo, en provenzal consérvanse nomes (dezaoito) e textos (vinte e tres) de trobairitz; en galego, nin tan sequera un indicio indirecto (Queizán 2011). ${ }^{3}$ A presenza

1 Existe a dúbida razoábel sobre se a Arte de Trobar o que fai é marcar unha taxonomía «inevitablemente post rem» (Sodré, 2008: 84) e, por tanto, descritiva do resultado do xa feito ou se, pola contra, parte dunha diferenciación previa, que se demostraría en que mesmo as variacións existentes dentro dun xénero «se llevaron a cabo sin voluntad de superar el sistema tripartito y, por lo tanto, sin la pretensión de crear nuevas categorías textuales más allá de la tríada amor-amigo-escarnio» (Gutiérrez 2009: 2). Iso estaría confirmado polo escaso peso que no trobadorismo galego teñen outras modalidades xenéricas.

2 Todo isto pódese atestar en liñas globais nos cancioneiros, aínda que existen importantes e interesantes excepcións, tanto nas diferenciacións amor / amigo como nas destes xéneros a respecto das sátiras. Así, algunhas dúbidas na adscrición dalgúns destes textos fai que se dean situacións tan interesantes como que no Cancioneiro da Ajuda, supostamente só con cantigas de amor, se inclúa algún escarnio que nunha primeira lectura podería non parecelo (p. ex., «Joana, dix’eu, Sancha e Maria», A 104 e B 212, de Pero Garcia Burgales) ou mesmo outras composicións que non teñen ningún contido amatorio, como o panexírico real «De quantas cousas eno mundo son» (A 256), de Paai Gomez Charinho. Do mesmo xeito, inclusive cando os cancioneiros se parecen ordenar por xéneros acaban mesturándoos, dándose casos de cantigas de amigo presentes na esperada sección das de escarnio e maldizer, e viceversa.

3 As diferenzas sobre a propiedade da terra e as posibilidades de herdanza das mulleres en Provenza e en Galiza (ou noutros reinos en que se trobou en galego nesta época) non explican esta situación, ao noso entender (discrepamos, pois, coa explicación de Queizán (2011: X).

Con certeza, non nos pode sorprender que, no plano xurídico, «con carácter xeral, a muller en abstracto non goza dunha cómoda posición nas disposicións legais da plenitude da Idade Media» (Pallares / Portela 2007: 112). Mais si debemos pensar que, xunto con esa desigualdade xudiciaria, no conxunto da Europa se daban situacións de relativo poder feminino entre a nobreza, entre as cales temos tamén numerosos exemplos no reino galego, aínda que é certo que os máis notorios son en tempos pretrobadorescos, como as raíñas Goto e Urraca da Galiza. Como concluíu María Milagros Rivera-Garreta (2005: 93), «la ajenidad de las mujeres hacia la política con poder fue, sorprendentemente, 
das mulleres no espectáculo trobadoresco galego si é indiciaria como mecenas (Vieira 1999) e moi notoria como soldadeiras. Estas últimas poderían traballar no espectáculo tanto na función de cantoras como na de danzarinas ou músicas, de forma illada ou con varios deses papeis ao mesmo tempo. Dúas caixas negras fundamentais que nos fornecen de información sobre o seu traballo artístico son as ilustracións que se conservan no Cancioneiro da Ajuda e as referencias das sátiras. ${ }^{4}$

A visión xeral, pois, é que as cantigas de amigo e de amor fan referencia a relacións heterosexuais idealmente imaxinadas como complementares (ela chorará por el; el chorará por ela). Por conseguinte, a procura dos repertorios relacionados co lesbianismo só se podería dar nas cantigas satíricas, que abordan este espazo mesmo nalgúns casos sen ambigüidade. Nesas cantigas satíricas, o desexo ou amor entre dúas mulleres revístese usualmente como un fantasma masculino, segundo a fórmula de Xuvenal lassata uiris necdum satiata, 'cansa dos homes, porén non saciada, non satisfeita' (Adams 1982: 103). ${ }^{5}$

No entanto, tamén decidimos realizar unha relectura demorada de todas as cantigas de amigo para entender se podía haber nelas algunha marca de afectividade interfeminina, por exemplo entre a muller que fala e as súas amigas, dentro da globalidade lesbian-like (Bennet 2000). ${ }^{6}$ Porén, non achamos ningún exemplo que puidese entrar dentro do noso campo de traballo con nitidez.

menor en la Europa feudal que en el Occidente capitalista. Son ejemplos de ello las abadesas y otras señoras feudales». No concreto do país galego, o historiador Xosé Ramón Fernández Pacios (2010) apunta que, nos matrimonios da Alta Idade Media, «algo sorprendente (...) que só acontece en Galiza, é que o home é quen dota á muller, a diferenza do que acontecerá noutras épocas».

Tampouco entramos na interesantísima focaxe de que os varóns se apropiarían dunha tradición de enunciación feminina, que para o caso do trobadorismo galego ten enunciado Ria Lemaire (1994, 1996), que desenvolveu verbi gratia Maria Lima Schantz (2005), e que tamén sustentou Rip Cohen nos seus estudos filolóxicos: «por muito que essa voz possa ser manipulada, os aspectos arcaicos destes poemas, a nível social, linguístico e musical, sugerem que essa voz é genuína nas suas origens» (Cohen, 2003: 59). Semella que o que temos son composicións escritas por varóns, mesmo que reelaboren cantos populares e de mulleres que hoxe non mantemos.

4Sabemos algunhas cousas sobre a autoría dos textos, mais no relativo á súa execución pública e por tanto oral, imaxinamos máis que o que coñecemos (cfr. Callón 2017, vol. 1: 82-89).

5 Elaboramos unha primeira panorámica sobre o lesbianismo nas cantigas de escarnio e maldizer no libro Amigos e sodomitas (Callón 2011: 101-113), que desenvolvemos con novos datos e máis matices en Callón (2017: 321-351).

6 Aínda que poidan existir concomitancias, e con certeza débedas argumentais, preséntanse como diferentes as teorías do continumm lésbico que propuxo Adrienne Rich e do lesbian-like: «Unlike Adrienne Rich, I do not wish to label all women-identified experience - from maternal nurturance and lesbian sadomasochism to the esprit de corps of an abortion rights march — on a lesbian continuum. The essence of Rich's continuum is 'primary intensity between and among women,' an intensity that involves both 'sharing of a rich inner life' and 'bonding against male tyranny.' Some behaviors that I would identify as lesbian-like — such as singleness — were not necessarily based in the female bonding at the center of Rich's analysis. To my mind, a singlewoman in a sixteenth-century European town, regardless of her emotional life, lived in ways relevant to lesbian history: she tended to be poor, in part because her household was not supported by the better earning power of men; she was viewed by her neighbors with some suspicion and concern; she could expect to be tolerated, if her conduct was above reproach in other respects. This singlewoman might have shared neither an emotional life nor any political commitment with other women, but her life circumstances were, in some respects, lesbian-like» (Bennet 2000: 15; itálicas no orixinal). 
Dentro dos estudos que se debruzan sobre a posibilidade da autoría feminina das primitivas cantigas de amigo, Maria Lima Schantz (2005) realizou unha analoxía entre o trobadorismo galego e o caso da poeta Safo, cuxa concepción erótica foi reutilizada e heterosexualizada noutros discursos amatorios posteriores:

\begin{abstract}
It is, indeed, very possible that Galician-Portuguese women lyricists were inspired by Sappho's homoerotic discourse of desire, passed down orally, to articulate their own heterosexual discourse of desire. And this hypothesis may very well account for the preservation of the theme of reciprocal love in the early cantigas de amigo. (Lima Schantz, 2005: 215)
\end{abstract}

Estas análises sobre as orixes, que permanecen con moitas hipóteses abertas, non podemos desenvolvelas con claridade no noso corpus. A única cantiga de amigo (ou en principio etiquetada como «de amigo») que entra nun repertorio lésbico, e ademais dun xeito explícito, é «Dizia la bentalhada», de Pedr'Eanes Solaz.

Antes de entrarmos na análise do texto, hai que dicir que xa de seu faría parte do noso tema de pesquisa pola insistencia de varias edicións en modificaren o xénero dun complemento directo, do feminino para o masculino, para que non se vise aí «a lesbian beloved (as some editors may fave feared)», como afirmou Rip Cohen (2003: 286) na súa edición de conxunto das cantigas deste xénero.

Como anexo presentamos unha edición do texto, mais pode verse con nitidez no manuscrito que a forma «Penada se a eu visse», do verso 7 , non é «Penada se o eu visse»:

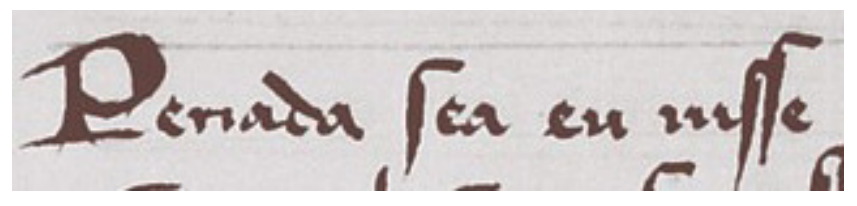

Imaxe 1, do Cancioneiro da Biblioteca Nacional de Lisboa

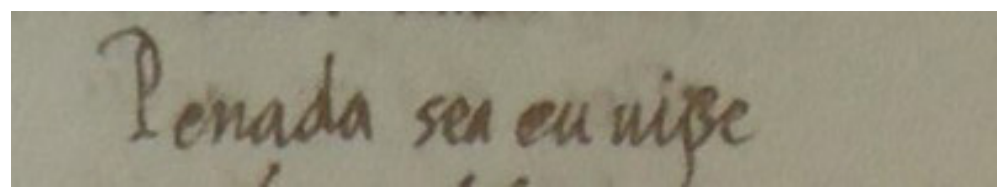

Imaxe 2, do Cancioneiro da Vaticana 
O mesmo acontece no verso 10 e con outras posíbeis segmentacións, masculinizadas contra todo criterio filolóxico válido. ${ }^{7}$

Aínda que o mesmo Rip Cohen mantén a grafía dos manuscritos, valora que aí non se estaría ante unha amada, senón ante unha rival:

[T] he feminine pronoun a in vv. 7 and 10 would be the only morphological indicator of the gender of the third persona - who is not, however, a lesbian beloved (as some editors may fave feared), but rather a rival, an Other Girl (Cohen 2003: 286).

É certo que é inesperábel un poema de amor entre dúas mulleres como os que si achamos na poesía mediolatina. Iso non se pode negar. Mais non hai ningunha forma de asegurar que aquí se estea a referir a unha contrincante nuns amores heterosexuais. Tanto é así que, como o propio Cohen recoñece, a maioría dos editores que deciden modificar o xénero é porque entenden a composición como un texto amatorio, non porque pensen que haxa ningunha competidora implícita nos versos.

A comprensión que realiza Rip Cohen do texto é esta:

\begin{abstract}
Nas estrofes I e II a construção pode ser assim parafraseada: «Quem me dera vê-la sofrer por quem eu sinto amor». Na estrofe III: «Porque se eu a visse sofrer, eu não estaria tão infeliz por quem eu sinto amor...». Na estrofe IV: «Não há dor que eu sentisse por quem eu sinto amor...». Nas estrofes V-VI: «Queria que alguém dissesse àquele por quem sinto amor que ele (por quem sinto amor) não se atrasasse mas chegasse...» - e aqui ond'eu amor ei funciona como oração relativa dependente de lh' e, juntamente com o seu antecedente omitido, constitui o sujeito gramatical de veesse, chegasse e non tardasse (e pode suplementarmente significar «ao lugar de onde» [...]) (Cohen 2003: 285).
\end{abstract}

É unha interpretación posíbel a que fai o grande editor, mais do noso punto de vista é un erro colocar con claridade unha figura masculina («àquele»e «ele»), cando o certo é que non existe ningunha marca lingüística que permita levar a esa conclusión. Nun estudo posterior (Cohen 2012: 85-86), dentro dun esquema sobre «Other Lovers in the Cantigas d'Amigo», aínda que se sinala con cautela que as personae aí actuantes son unha moza e unha figura non identificada (repárese no primeiro verso), despois indícase que o movemento da composición é «I wish I could get him back from O[ther]» (Cohen 2012: 86; itálica acrecentada). A verdade é que non existe ningún him.

7 Este tipo de modificacións de xénero por unha cosmovisión heterosexista da man editora son habituais na Historia da literatura, como analizamos en Callón (2003). No ámbito concreto da literatura medieval e en concreto da galegoportuguesa son varios os exemplos que se poderían citar, como en textos atribuídos a Nuno Porco ou Pero da Ponte (Callón 2017). Un caso destacábel é o dun autor xa postrobadoresco, Alfonso Álvarez de Villasandino. Os editores, ao se encontraren con que na composición se dicía que outro poeta ía ter «maridos», chegaron a propor como hipótese un disparatado «maridas», inaceptábel desde a crítica textual (Dutton / González Cuenca 1993: 136). 
Pola súa vez, nun artigo escrito a catro mans por Rip Cohen e Federico Corriente, suxerían que o texto faría parte dun «lyric drama» representado nunha «mini-sequence of two songs» (Cohen / Corriente, 2002: 25) de Pedr'Eanes Solaz. A outra cantiga sería «Eu velida non dormia» (B 829 / V 415), unha enigmática poetización da insomnia amorosa. O coñecido refrán dese texto, edoi leliadoura, tivo diferentes interpretacións ao longo do tempo. Por exemplo, Braga (1878: CII) afirmaba con certa contundencia que se trataba dunha onomatopea galega, ${ }^{8}$ mais desde a década de 60 do século XX concluíuse que estaba en árabe, embora as traducións sobre o que o texto árabe (se callar, cun fragmento en romandalusí?) diría foron mudando co tempo. Para Brian Dutton (1964: 1-9) e Olga Novo (2013: 82 e 86) sería sobre a noite que dura e se fai longa, unha idea que ten ligazóns directas con outras composicións dos nosos códices, como as lindísimas «Sen meu amigo manh'eu senlheira» (B 1165 / V 771) e «Aquestas noitas tan longas, que Deus fez en grave dia» (B 1176, V 782), ambas de Juião Bolseiro.

Por outra banda, para Rip Cohen e Federico Corriente o refrán significiaría «it's my turn» (Cohen \& Corriente, 2002: 27), 'é a miña vez'. Nesa lectura, nos dous textos seleccionados de Pedr'Eanes Solaz habería implícita unha muller que se dirixiría a outra opoñente feminina no amor dun amigo que ambas partillarían. Os investigadores explican que iso habería que encadralo dentro da tradición islámica, que ficaría evidenciada polo uso do árabe no refrán intercalar:

[A] typically Islamic folkloric item: jealousy between several women belonging to one man as slaves or entitled to his love as legal wives, which led to rivalry, insults or even acts of aggression, and to attempts to take the rival's place or turn in the beloved's affection or bed (Cohen \& Corriente 2002: 31).

Do noso punto de vista, sempre son de agradecer as relecturas críticas que rompen coa acumulación repetida de interpretacións, porén non podemos coincidir con estas conclusións. Por unha banda, é moi importante que non exista ningún outro exemplo na arte trobadórica galega «que faga referencia ao amor 'por quendas' dos usos amorosos dun harén» (Novo 2013: 84). Alén diso, os textos en que sustentan a súa teoría non transparecen

situación ningunha de rivalidade e, aínda máis, non sen entende por que estas dúas cantigas constituirían unha «mini-escena», quedando excluídas do relato as demais cantigas compostas por Eanes Solaz (Novo 2013: 84).

$8 \mathrm{O}$ erudito portugués afirma que ese refrán (que interpreta como «Lelia d’outra - E doy Lelia d'outra») sería nin máis nin menos que «o estribilho nacional da Galliza, a neuma característica da sua poesia popular», que despois emparentaría cos «cantos populares das provincias vascongadas» (Braga 1878: CII). Permítasenos comentar aquí a facilidade con que algunha persoas, mesmo algunha con grande sensibilidade e moito interese polos estudos galicianistas en particular, tentaron desde o XIX até o XXI atribuír sen ningunha proba ás falas galegas aqueles termos que non eran capaces de comprender nos cancioneiros. Imaxinemos que é o que acontecería academicamente se se pretender dicir que tal ou cal palabra está viva en Portugal contra toda evidencia pragmática e sen ningunha proba bibliográfica.

SCRIPTA, Revista internacional de literatura i cultura medieval i moderna, núm. 15 / juny 2020 / pp. 1 - 15 
O punto en que máis coincidimos nas palabras de Olga Novo é na seria dificultade de tentar vincular ou non unhas cantigas con outras, ${ }^{9}$ pois neste caso concreto non vemos ningún indicio que nos permita sustentar que exista un conxunto ligado, para alén de seren dúas composicións consecutivas nos códices (B 828 / V 414 e B 829 / V 415) e de que ambas teñen dificultades -aínda que diversas- para a súa comprensión.

Aquilo en que xa non concordamos coa profesora galega é en que considera que nos textos non haxa probas da «mención a outra mullen» (Novo 2013: 84). Isto acontece porque consultou unha edición adulterada do texto (Novo 2013: 83), onde ou non se identificaron (vv. 2 e 5) ou se reescribiron en masculino os pronomes femininos de complemento directo (vv. 7 e 10) da cantiga, como se pode comprobar na edición con que fechamos este artigo. Sobre a cuestión da rivalidade, entendemos que, no entanto, sen ser conclusiva (ningunha das hipóteses que aquí barallamos é conclusiva), si é coherente como posibilidade por analoxía con outras composicións, mesmo que tamén teña os seus défices porque, con certeza, non é en absoluto evidente na propia cantiga.

Hai aínda un outro elemento importante. Se se estiver de acordo cun «Islamic folkloric item» (Cohen \& Corriente 2002: 31), é unha lectura máis sinxela considerar a expresión dun tema lésbico, sobre o cal hai abondos testemuños nesa tradición literaria, como referimos no capítulo 5 desta disertación. Non coñecemos que haxa rastro de haréns nas cortes en que se trobou en galego-portugués; si temos probas claras, a través do rexistro satírico, de mulleres que amaron outras mulleres, mesmo coa parquidade de testemuños que conservamos do lesbianismo (Callón 2017: 321-351).

Sinalamos antes que a opción da rival si debería valorarse, tendo en conta a identificación explícita desa figura na tradición interna das escolas trobadorescas (Cohen 2012: 61-86), por exemplo nesta primeira estrofa de Juião Bolseiro (B 1174 / V 780):

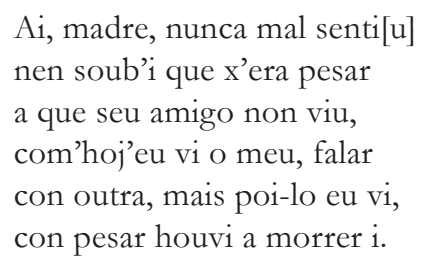

É unha hipótese plausíbel que a outra, que aquí figura ben explícita no primeiro verso do refrán, sexa tamén a figura que se presentifica nas primeiras estrofas da cantiga de Pedr'Eanes Solaz. O problema está nas dúas últimas cobras. Na opinión de Cohen, nese caso o pronome lhe sería a

9Son varios os investigadores e as investigadoras que teñen defendido a existencia de certas secuencias de cantares organizados para a súa representación. É por exemplo o caso de Francisco Nodar Manso (1983 e 1990), con textos escarniños ou maldicentes de Lopo Lias (cfr. Callón 2007, vol. 1: 300-314). Tamén Rip Cohen (1987) o propuxo con composicións de amigo de Don Denis. Se esas non probadas ordenacións existiren nas cantigas amatorias, «these would be the first sequences of love songs in any vernacular language in the history of European literature, providing a unique opportunity to study the evolution of a lyric-dramatic artform from its constituent parts» (Cohen 2003: 31).

SCRIPTA, Revista internacional de literatura i cultura medieval i moderna, núm. 15 / juny 2020 / pp. 1 - 15 
marca do amante masculino, mais non existe ningunha viraxe lingüística que nos amose que no último par de estrofas se mudase o referente feminino presente até aí. Erilde Reali (1962: 182), na súa edición de Pedr'Eanes Solaz, expón que neste refrán se expresa un «lamento monocorde»a través do cal a dor da moza «sembra mitigarsi nella compiaciuta ripetizione verbale dell'oggetto della sua pasione».

A cantiga comeza cunha enunciación sen identificar (quizais o quen dos vv. 13 e 16?), que é testemuña do que ouviu dicirlle á ben-talhada, á bela, a quen se lle transfire a voz a continuación. A muller expresa o seu desexo de ver penada unha outra figura feminina, no lugar onde ela ten agora amor. No segundo par de cobras, a ben-talhada sinala que se vise que esa figura feminina está triste, ela non estaría tan mal. Xa nas derradeiras estrofas, desexa que alguén lle dixese (suponse que á figura feminina até aí referida) que fose ao seu encontro. O refrán marca o amor topograficamente: o desexo é ver a tristura e o reencontro nun espazo concreto. Transmítesenos ademais o movemento desde o despeito até o desexo da reconciliación, mais sempre a dependencia afectiva.

Débese atender, no entanto, a que o adverbio onde do refrán non ten só un valor de indicación espacial, senón que pode posuír tamén o contido semántico de 'persoa', como teñen valorado nos seus estudos Rip Cohen (2003: 286) e Elsa Gonçalves (2016: 575-576). Proviría dun uso xa atestado do UNDE latino, do cal tamén existe cando menos un exemplo con u nos nosos cancioneiros (Gonçalves 2016: 575-576). Aurora Juárez Blanquer, nunha ocorrencia deste onde metafórico en Pero da Ponte, defíneo así: «Se refiere más bien a la persona que al lugar. Es el lugar como hábitat de la persona» (Juárez Blanquer 1988: 108).

O primeiro problema para podermos aproveitar este coñecemento na cantiga sobre a que nos estamos a debruzar é que semella que o significante reiterado no refrán non ten o mesmo peso semántico en cada unha das estrofas. Cando menos, parece que no último par ten un sentido máis adverbial. Outra dificultade non menor é cal sería a significación que tería nas outras cobras: 'de quen', 'da persoa por quen', 'pola persoa por quen'... Os pequenos matices poden mudar -cando menos levemente- o sentido, e non se nos fornecen chaves indubidábeis para optarmos por unha ou outra lectura.

Como conclusión deste percurso analítico, debemos dicir que, aínda que a posibilidade da antagonista non se poida descartar, non nos parece a opción máis probábel, tanto pola inexistencia dun obxecto de desexo masculino nos versos como pola mudanza drástica que suporían as dúas últimas estrofas a respecto do resto da composición.

Que haxa algún revés satírico neste poema non nos semella unha hipótese válida. Aínda que iso fixese máis concibíbel a existencia dun poema erótico entre dúas mulleres, o léxico limpo e sen fendas para a equivocatio que se utiliza ao longo da composición non abre esas portas. 
Debe pórse tamén sobre a mesa a posibilidade de que sexa un canto de afecto entre dúas damas, mesmo coa opción dunha amizade traizoada. Aquí encontrámonos cun pro e cun contra: que non é un motivo que teña parangón na literatura dos espazos cristiáns, mais que si o ten na dos espazos árabes, coa cal, de novo, podemos supor vinculado a Pedr'Eanes Solaz.

Déaselle preferencia ou non, debe valorarse seriamente a posibilidade (asentada fantasmaticamente ademais polos editores que decidiron mudar o testemuño dos cancioneiros e clarificar a heterosexualidade dos versos) de que sexa o sentimento de coita que sente a moza namorada, que desexa o reencontro coa súa amada. Posúe todo o sentido lingüístico na cantiga, mais ten o problema de que sería algo inagardado e que só tería outro poema semellante no trobadorismo, o exemplo occitánico «Na Maria, pretz e fina valors», atribuída a Bieirs de Romans.

No caso deste texto provenzal, tamén hai quen entende que a muller a quen se dirixe non se trata dunha amada real, senón dunha forma de se referir á Virxe María, ou tan só dunha «intimate friend» (Rieger 1984: 90), algo que parece difícil á luz do erotismo de varios deses versos (Bec 1989: $197-$ 200; Cabana 2011: 424-427 e 598-599).

No entanto, tal e como está escrito e como funcionou o poema non existe necesidade dunha disxuntiva: pódense activar varios sentidos ao mesmo tempo e non de forma contraditoria. Houbo tamén outras propostas críticas para o consideraren escrito por un home, en especial a un trobador que se chamaría N'Albric, posibilidade que descarta o editor e tradutor Darío Xohán Cabana con contundencia:

\footnotetext{
Sendo obra de trobairitz, parece impoñerse a interpretación deste poema como de amor lésbico. Mais tamén niso hai opinións pra outros gustos, e aínda que non nos parezan acertadas talvez se poidan defender algo mellor cá atribución a N'Albric, postulada por Schultz-Gora, por Bertoni ou por Jeanroy. Non puiden ler o primeiro — non sei alemán—, pero o machismo e a pudibundez dos outros poden explicar en parte a súa boa disposición ó negacionismo (...). (Cabana 2011: 598)
}

Outra crítica, Angelia Rieger (1989), considera que se trata máis duns versos en que se manifesta unha forma de concibir o afecto entre mulleres que é moi diferente á actual e rexeita as lecturas previas que etiquetaban a composición como lésbica. Na conclusión da súa análise recoñece, no entanto, que, a pesar do seu escepticismo sobre a cuestión, hai algunhas liñas de amor interfeminino que non se poden descartar: «The possibility of an element of female jealousy (which might even bear lightly homoerotic characteristics) need not be ruled out entirely» (Rieger 1989: 92).

Pola súa parte, Peter Dronke analizou nos seus estudos sobre a lírica amatoria europea tres casos de epístolas en latín escritas en Baviera por cadansúas monxas que expresaban as saudades por outras relixiosas. Eses e o atribuído a Bieirs de Romans son os únicos textos en que encontramos amores lésbicos relatados en primeira persoa por unha sinatura autorial de muller. O quinto caso das literaturas europeas, mais asinado por un varón, é «Dizia la ben-talhada». 
Dronke é moi claro e considera amatorios e non simplemente amicais os tres exemplos sobre os que se debruza. Un deles, mesmo «seems to presuppose a passionate physical relation» (Dronke 1968: 482), xa que fala do recordo de cando a súa amada acariciaba os seus peitos.

Como vemos, «Dizia la ben-talhada» non sería un exemplo único.

Para alén deses outros casos, a favor da interpretación lésbica está tamén que é o sentido que implica menos mudanzas ou segmentacións no texto; ademais, podería ser un esforzo por parte do autor de expresar outra faceta do desexo feminino a través dunha cantiga de amigo, que fai serie con outras tentativas de se achegar ao erotismo das mulleres neste xénero. Nun trobador que coñece a tradición literaria árabe tamén se ve máis factíbel esa posibilidade. ${ }^{10}$ Lembremos, por exemplo, que no século XII o reino de Granada vai ter un importante grupo de mulleres poetas, hipoteticamente polas influencias bereberes que tiveron nese tempo, e que conservamos poemas literalmente lésbicos como o seguinte, que presentamos na súa tradución para o castelán:

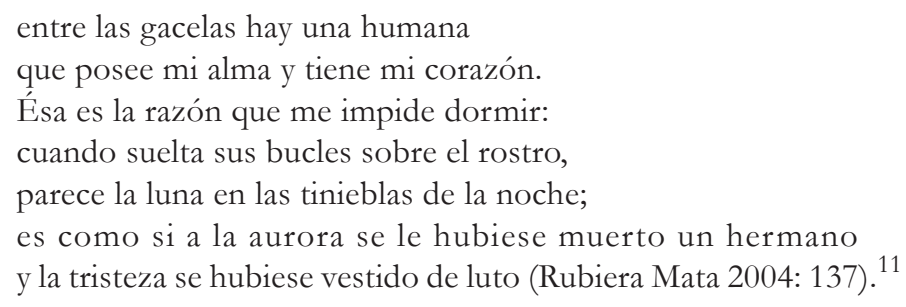

Unha composición como «Dizia la ben-talhada» testemúñanos que aínda fican moitos importantes camiños por transitar nos estudos da literatura medieval en xeral e no do trobadorismo galegoportugués en concreto. Co percurso deses vieiros poderemos lograr unha relevante información literaria, filolóxica, social e histórica.

\footnotetext{
10 Por outra banda, embora dun xeito máis feble, tamén xoga a favor desa interpretación o feito de que nesta época non hai ningunha condena civil contra o lesbianismo, mais nese caso está en contra o feito de que esa condena non existe, entre outras razóns, porque tampouco se formula como algo imaxinábel na Cristiandade que poida haber ese relacionamento sólido entre mulleres.

11 Dubídase entre a autoría de dúas mulleres, as irmás Ziyad de Guadix, Zainab e Hamda.

A súa tradutora indica sobre ese texto: «nos deja en la duda de si se trata de un tópico literario o de homoerotismo» (Rubiera Mata 2004: 137). Tírese o prefixo homo- e aplícase a calquera texto amatorio de calquera época. O curioso é que ese tipo de reflexións só se produzan cando existe dito prefixo. O heterosexismo convértenos a todas e todos en heterosexuais mentres non se demostre o contrario e, ás veces, mesmo que se demostre.
} 


\section{ANEXO: EDICIÓN DA CANTIGA «DIZIA LA BEN-TALHADA”}

Dizia la ben-talhada:

“Agor'a viss'eu, penada, ond'eu amor heì.

A ben-talhada dizia:

$5 \quad$ "Penad'a viss'eu un dia

ond'eu amor bei.

Ca, se a viss'eu, penada, non seria tan coitada

ond'eu amor bei.

10 Penada, se a eu visse,

non ha mal que eu sentisse

ond'eu amor hei.

Quen lh'hoje por mí rogasse

que non tardass'e chegasse

15 ond'eu amor hei.

Quen lh'hoje por mí dissesse

que non tardass'e veesse

ond'eu amor heì.

MANUSCRITOS: B 828 / V 414.

EDICIÓNS: Braga (1878: 78). Nunes (1912: 351-352). Paxeco \& Machado (1949-1964, IV: 138139). Nunes (1971: 212-213) [= Base de datos da lírica profana: 117,2]. Reali (1962: 180-182). Cohen (2003: 285). Lopes \& Ferreira et al. (2011). ${ }^{12}$ [A edición actual é =Callón (2017, vol. 2: 30-32)].

$12<$ https: / cantigas.fcsh.unl.pt/cantiga.asp?cdcant $=837 \& p v=\operatorname{sim}>$ [últ. cons., 20/05/20] 


\section{NOTAS}

As dúas últimas estrofas aparecen en orde inversa en V. Seguimos a lección de B, como o resto das editoras e editores, excepto Braga, Nunes (1912 e 1971) e Reali.

2. Coincidimos coa segmentación realizada por Cohen, Agor'a, na liña da marcada por Paxeco / Machado: Agor a.

3, 6, 9, 12 e 15. Reali edítao con sinal de exclamación nas primeiras tres cobras (vv. 3, 6 e 9) e con interrogación nas dúas derradeiras (vv. 12 e 15).

5. Son posíbeis diferentes segmentacións deste verso, como Penada, viss'eu un dia, de Nunes, Reali e Projeto Littera. Optamos pola mesma lectura que realizou Cohen, tamén coa segmentación Penad'a.

Baseándose na literalidade dos manuscritos, que é uiss enhĩ (B) e uisse nhũ (V), Braga editou Penada, visse n'bum dia e Paxeco / Machado penad a uisse en ũ dia. Porén, semella que aquí os testemuños confunden $<\mathrm{n}>/<\mathrm{u}>$, embora coa preposición o verso tamén faga sentido.

7. En B e V, Cassea nisseu penada. Varias das edicións cotexadas (Nunes -e, en consecuencia, a Base de datos da Lírica Profana-, así como Reali e o Projeto Littera de Lopes / Ferreira) modifican o pronome $a$ en 0 . Tamén acontece o mesmo en antoloxías, como a de Álvarez Blázquez (1975: 60). Como apuntou Cohen, o máis probábel é que interpretasen que ese sería un amor lésbico e que, contextualmente, en comparación coas outras cantigas conservadas, non lle visen sentido.

10. En B e V, Penada sea eu uisse. Acontece o mesmo que o comentado no v. 7. 


\section{Bibliografía}

Adams, J. N. (1982) The Latin Sexual Vocabulary, Londres, Duckworth.

Álvarez Blázquez, X. M. (1975) Escolma da poesía medieval (1198-1354), Vigo, Castrelos.

Base de datos da Lirica Profana Galego-Portuguesa (en liña), <http://www.cirp.gal/meddb>, Santiago de Compostela, Centro Ramón Piñeiro para a Investigación en Humanidades [últ. cons., 02/04/2017].

Bec, P. (1984) Burlesque et obscénité chez les troubadours, París, Stock.

Bennet, J. M. (2000) «Lesbian-like ante the social history of lesbianism», Journal of the History of Sexuality, 9, pp. 1-24.

Braga, T. (1878) Cancioneiro portuguez da Vaticana. Edição crítica, Lisboa, Imprensa Nacional.

Cabana, D. X. (2011) Os trobadores de Occitania, Lugo, Da Curuxa.

Callón, Carlos (2003): Implicacións institucionais do heterosexismo no campo literário. Aproximacións ao caso galego e linas de pesquisa, Santiago de Compostela, Universidade de Santiago de Compostela, Traballo de Investigación Tutelado inédito.

—. (2011) Amigos e sodomitas. A configuración da homosexualidade na Idade Media, Santiago de Compostela, Sotelo Blanco.

- (2017) As relacións sexoafectivas intermasculinas e interfemininas no trobadorismo galego, A Coruña, Universidade da Coruña, tese de doutoramento inédita.

Cohen, R. (1987) Thirty-two Cantigas d'amigo of Dom Dinis: Typology of a Portuguese Renunciation, Madison, The Hispanic Seminary of Medieval Studie.

—_. (2003) 500 Cantigas d'Amigo, Porto, Campo das Letras. [Trad. Isabel Rodrigues.]

. (2012) Erotic angles on the Cantigas d'amigo, Londres, University Of London.

Cohen, R. \& Corriente, Fe. (2002) «Lelia doura Revisited», La corónica. A Journal of Medieval Hispanic Languages, 31, pp. 19-40.

Dronke, Pe. (1984) The Medieval Poet and His World, Roma, Edizioni di Storia e Letteratura.

Dutton, B. (1964) «Lelia doura, edoy lelia doura, an arabic refrain in a thirteenth-century Galician poem?», Bulletin of Spanish Studies, 41, pp. 1-9.

Dutton, B. \& González Cuenca, J. (1993) Cancionero de Juan Alfonso de Baena, Madrid, Visor.

Fernández Pacios, X. R. (2010) «O papel da muller na nosa alta idade media», Terra e Tempo, 11 de agosto de 2010, <http://terraetempo.gal/artigo.php?artigo=729\&seccion=13> [últ. cons., 03/11/2016].

Gonçalves, E. (2016) De Roma ata Lixboa. Estudos sobre os cancioneiros galego-portugueses, A Coruña, Real Academia Galega.

Gutiérrez García, S. (2009) «Paralelismo y refrán en la configuración de los géneros líricos gallegoportugueses», Ars Metrica, 9, <http://arsmetrica.elte.hu/articles/gutierrez/0910_gutierrez. pdf> [últ. cons., 05/11/2016]. 
Juárez Blanquer, A. (1988) Cancionero de Pero da Ponte, Granada, TAT.

Lima Schantz, M. (2005) A Feminist Interpretation of the Galician-Portuguese Cantigas de Amigo, Lewiston / Queenston / Lampeter, Edwin Mellen Press.

Lopes, G. V. \& Ferreira, M. P. et al. (2011-), «Pedro Anes Solaz. Dizia la bem talhada» in Cantigas Medievais Galego Portuguesas [base de dados online], Lisboa, Instituto de Estudos Medievais < http:/ / cantigas.fcsh.unl.pt> [últ. cons., 20/05/20].

Nodar Manso, F. (1983) Narrativa arquetípico-novelesca y narrativa dramática de la poesía galaicoportuguesa medieval, s. 1. [Montreal], McGill University, tese de doutoramento inédita.

- (1990) Teatro menor galaico-portugués (siglo XIII). Reconstrucción contextual y teoría del discurso, Kassel, Universidad de La Coruña / Edition Reichenberger.

Novo, O. (2013) Leda m'and'eu. Erótica medieval galaica, Noia, Toxosoutos .

Nunes, J. J. (1912) Crestomatia arcaica. Excertos da literatura portuguesa desde o que de mais antigo se conbece até o século XVI, Lisboa, Portugal-Brasil Limitada.

—. (1971) Cantigas d'amigo dos trovadores galego-portugueses, 3 vols., Nova York, Kraus Reprint.

Pallares, M. C. \& Portela, E. (2007) «De Xelmírez aos Irmandiños. A Galicia feudal (séculos XII-XV)», vol. II, A Gran Historia de Galicia, Xosé Ramón Barreiro e Ramón Villares (eds.), A Coruña, La Voz de Galicia.

Paxeco, E. \& Machado, J. P. (1949-1964) Cancioneiro da Biblioteca Nacional, antigo Colocci-Brancuti, 8 vols. (I, 1949; II, 1950; III, 1952; IV, 1953; V, 1956; VI, 1958; VII, 1960; VIII, 1964 ), Lisboa, Edição da 'Revista de Portugal'.

Queizán, M. X. (2011) Escribir en nome propio, Vigo, Xerais.

Reali, E. (1962) «Il canzoniere di Pedro Eanes Solaz», Annali dell'Istituto Universitario Orientale. Sezione Romanza, vol. 4, fasc. 2, pp. 167-195.

Rieger, A. (1989) «Was Beiris de Romans Lesbian? Women's Relations with Each Other in the World of the Troubadours» in The voice of the Trobairit: Perspectives on the Women Troubadours, William D. Paden (ed.), Filadelfia, University of Pennsylvania Press, pp. 73-94.

Rivera Garreta, M.-M. (2005) La diferencia sexual en la historia, València, Publicacions de la Universitat de València.

Rubiera Mata, M. J. (2004) Literatura hispanoárabe, Alacant, Universidad de Alicante.

Sodré, P. R. (2008) Cantigas de madre galego-portuguesa, Santiago de Compostela, Xunta de Galicia .

Vieira, Y. F. (1999) En cas dona Maior. Os trovadores e a corte senhorial galega no século XII, Santiago de Compostela, Laiovento . 